\title{
A new long-acting GLP-1 derivative KTP ameliorates hyperglycemia and dyslipidemia and improves pancreas and fatty liver in $\mathrm{db} / \mathrm{db}$ mice
}

\author{
SANG YanXia, ZHOU TianHong ", LI HongJian, RAN YanHong, JIANG DeQi, ZHENG Fei, \\ CHEN Ying, WANG CongFeng \& ZOU Xin
}

College of Life Science and Technology, Jinan University, Guangzhou 510632, China

Received January 30, 2013; accepted March 27, 2013; published online June 5, 2013

\begin{abstract}
Glucagon-like peptide-1 (GLP-1) is a polypeptide incretin hormone that glucose-dependently promotes the secretion and synthesis of insulin. However, its half-life is extremely short. To enhance its half-life, we developed a long-acting GLP-1 derivative KTP with controlled release, designed on the basis of another GLP-1 derivative GP62. The kinetics and bioactivity of KTP were evaluated in Sprague Dawley (SD) rats. Long-term treatment of KTP was performed in $d b / d b$ mice. Mice were treated twice daily with subcutaneous injections of KTP (1.2 mg/kg body weight), Exendin-4 $(0.1 \mathrm{mg} / \mathrm{kg}$ body weight) or vehicle (phosphate buffered saline (PBS), pH 7.4) for $60 \mathrm{~d}$. KTP had a longer half-life, as well as further increasing the secretion and production of insulin and reducing blood glucose concentrations, than GP62. Long-term treatment with KTP also induced anorexia, decreased water and food intake, decreased weight gain, improved blood glucose and blood lipid and ameliorated pancreatic damage and fatty liver in $d b / d b$ mice.
\end{abstract}

GLP-1, KTP, derivative, $d b / d b$ mice, type 2 diabetes

Citation: Sang Y X, Zhou T H, Li H J, et al. A new long-acting GLP-1 derivative KTP ameliorates hyperglycemia and dyslipidemia and improves pancreas and fatty liver in $d b / d b$ mice. Chin Sci Bull, 2013, 58: 2447-2453, doi: 10.1007/s11434-013-5915-y

Glucagon-like peptide 1 (GLP-1) is an important glucose dependent incretin hormone secreted by $L$-cells in the gastrointestinal tract [1-3]. GLP-1 reduces blood glucose concentration via glucose-dependent stimulation of insulin secretion [4]. GLP-1 also delays gastric emptying [5,6] and has been shown to directly stimulate the growth and proliferation of $\beta$ cells [7]. Although GLP-1 has anti-diabetic potential [8-14], its native form, has a biological half-life of only a few minutes ( $<2 \mathrm{~min}$ ) because of its very rapid degradation in plasma by dipeptidyl peptidase IV (DPPIV) $[15,16]$. Its transient lifetime has limited the use of GLP-1 to treat non-insulin-dependent diabetes mellitus (NIDDM).

Efforts to improve the pharmacokinetics of GLP-1 have included structural modifications, coadministration of competitive inhibitors and the use of various delivery systems $[17,18]$. Recently, a promising protease-based controlled

*Corresponding author (email: tzth@jnu.edu.cn) release strategy was reported [19]. GP62 polypeptide, a derivative of GLP-1, was designed according to this strategy and was found to slowly and continuously release bioactive GLP-1 through protease hydrolysis. Subcutaneously administered GP62 reduced blood glucose concentrations and acted over $10 \mathrm{~h}$ in GK rats. However, GLP-1 acted only for $1.5 \mathrm{~h}$.

GP62 has a sequence of LPHSHRAHSLPPFNPRGP(GLP-1) and contains three function domains, an albuminbinding domain (ABD, LPHSHRAHSLPP), a proteasecleavable linker (LK, FNPRGP) and bioactive GLP-1. LK is recognized and cleaved by thrombin and DPPIV. In vivo, GP62 can associate with serum albumin through ABD, enhancing its half-life in circulation. Dissociating from serum albumin, GP62 is hydrolyzed orderly by thrombin and DPPIV in the blood and releases coupled GLP-1 slowly.

To further improve the controlled release of GP62, $\operatorname{Arg}(\mathrm{R})$ Gly $(\mathrm{G})$ in the LK of GP62 was replaced by Lys(K)-Thr(T), 
generating a new GLP-1 derivative polypeptide, KTP, with the sequence LPHSHRAHSLPPFNPKTP-(GLP-1). We evaluated the kinetics and bioactivity of KTP in SD rats and its long-term effects on food and water intake, body weight, blood glucose, blood lipids, pancreas and fatty liver in the $d b / d b$ mouse model of type 2 diabetes.

\section{Materials and methods}

\subsection{Materials}

Male SD rats (280-300 g) were obtained from the Animal Center of Guangdong Medical Experiments, and $d b / d b$ mice (25-30 g) were purchased from ARLMATE Ltd. The animals were housed in stainless steel hanging cages (three to four per cage) under standard laboratory conditions $(12: 12$ light: dark cycle, temperature $25-27^{\circ} \mathrm{C}$, humidity $50 \%-60 \%$ ), with free access to food and water. All animals were monitored for 2 weeks prior to any experimental procedures.

Unless otherwise indicated, all reagents were of the highest quality commercially available.

KTP and GP62 were prepared in the Biochemistry and Molecular Biology Laboratory (Jinan University). The gene encoding KTP was cloned into E. coli BL21 (DE3) and expressed in fusion protein form following induction by isopropyl $\beta-D$-1-thiogalactopyranoside. The fusion protein was purified by Ni-NTA affinity chromatography, hydrolyzed with formic acid to remove tag peptide, and again purified by Ni-NTA affinity chromatography and HPLC. Mass spectrometry analysis showed a KTP purity of $96.9 \%$. GA62 was prepared similarly, yielding a purity of $97.3 \%$.

Exendin-4 (HOR-269) was purchased from ProSpecTany TechnoGene Ltd.

\subsection{Experimental design}

(1) Kinetics of plasma KTP. Two groups of SD rats ( $n=8$ per group) were each injected subcutaneously with KTP and GP62 (1.2 mg/kg body weight each). Blood from the tail vein was collected into heparinized capillary tubes before injection and at 1, 2, 2.5, 3, 4, 5, 6, 8, 10, 12, 16, 20, 28,36 and $48 \mathrm{~h}$ after injection. Samples were kept on ice until plasma was separated by centrifugation. The sample times were based on the preliminary experiments and were designed to determine the time to the maximum plasma concentration $\left(T_{\max }\right)$ of KTP and GP62.

(2) Insulinotropic activity test. Eighteen male SD rats were fasted overnight, randomized into 3 groups ( $n=6$ per group) and each injected subcutaneously with KTP $(1.2 \mathrm{mg} / \mathrm{kg}$ body weight), GP62 (1.2 mg/kg body weight) or an equal volume of vehicle (PBS, pH 7.4) $30 \mathrm{~min}$ before glucose loading. At time 0 , each rat was orally administered glucose ( $2 \mathrm{~g} / \mathrm{kg}, 50 \%$ glucose solution) by gavage. Blood samples were taken from the tail vein into heparinized capillary tubes at $-30,0,15,30,45,60,75,90,120$ and 150 min and kept on ice until the plasma was separated by centrifugation.

(3) Hypoglycemic effect. Three groups of $d b / d b$ mice ( $n=8$ per group) each were subcutaneously injected with KTP (1.2 mg/kg body weight), GP62 (1.2 mg/kg body weight) or an equal volume of vehicle, with dose volumes based on pretreatment body weight. Blood samples were collected from the tail vein for blood glucose analysis before and 1, 3, 5, 7, 9, 12 and $24 \mathrm{~h}$ after injection.

(4) Long-term treatment experiment of $d b / d b$ mice with KTP. Three groups of $d b / d b$ mice ( $n=8$ per group) each received two daily subcutaneous injections, at 08:30 and 19:30, of KTP (1.2 mg/kg body weight), Exendin-4 (0.1 $\mathrm{mg} / \mathrm{kg}$ body weight) or vehicle for $60 \mathrm{~d}$. Dose volumes were based on pretreatment body weights and ranged from 0.1-0.2 mL per mouse. Food and water intake were measured daily, and the animals were weighed weekly between 09:00 and 11:00. Following a 2-day drug-free recovery period, oral glucose tolerance test (OGTT) was performed, and blood was obtained by puncture of the orbital venous plexus with glass capillary tubes. The animals were euthanized, and the pancreas and liver of each were rapidly removed and stored in buffered formalin (4\%).

\subsection{Oral glucose tolerance test}

Following an overnight fast (16 h), each animal was administered glucose $(2 \mathrm{~g} / \mathrm{kg}, 50 \%$ glucose solution) into the stomach using a gavage needle. Blood was taken from the tail vein at $0,5,10,20,30,60,120$ and $180 \mathrm{~min}$.

\subsection{Measurement of blood parameters}

Blood glucose concentrations were measured by one touch Ultra (Johnson \& Johnson, USA). Blood samples for kinetic analysis or insulin measurement were centrifuged at $2000 \times g$ for $10 \mathrm{~min}$ at $4^{\circ} \mathrm{C}$, and the resulting plasma samples were placed into cryotubes, which were stored at less than $-18^{\circ} \mathrm{C}$ pending analysis. Plasma concentrations of KTP and GP62 were determined by double sandwich ELISA using a capturing antibody (ABS 046-03, BioPorto, Denmark), detecting antiserum (rabbit anti-LK of KTP or GP62, Baiaotai Biological Technology Co., Ltd., China) and rat anti-rabbit IgG-HRP (4065-05, SouthernBiotech, USA). Plasma insulin concentrations were estimated using Ultra Sensitive Rat Insulin ELISA Kits (90060, Crystal Chem, USA) according to the manufacturer's protocol.

Blood lipids were analyzed by a biochemical autoanalyzer (Wako, Japan).

\subsection{Histology}

Tissue sections were prepared and stained with hematoxylineosin (H\&E) as described [20]. After sacrifice, the pancreas and liver of each animal were fixed overnight in $4 \%$ paraformaldehyde, fractionated, dehydrated, embedded and 
sectioned at $5 \mu \mathrm{m}$. The sections were stained with $\mathrm{H} \& \mathrm{E}$ and examined by light microscopy (Olympus BX51 Microscope, Japan).

Immunohistochemical staining was performed as described [21]. Antigen retrieval was performed using citrate buffer ( $\mathrm{pH}$ 6.0), and endogenous peroxidases were quenched with $3 \%$ hydrogen peroxide. Sections of pancreas were incubated orderly with rabbit anti-insulin antibody (15848-1AP, Proteintech Group, USA) for $2 \mathrm{~h}$ and with a biotinylated secondary antibody (4010-08, SouthernBiotech, USA) for $1 \mathrm{~h}$, with expression detected by reaction with horseradish peroxidase-streptavidin-biotin complex and 3,3'-diaminobenzidine tetrachloride (DAB). All sections were counterstained with Mayer's hematoxylin.

\subsection{Statistical analysis}

Data are expressed as mean \pm standard error (SE), with between groups differences assessed using Student's $t$-test or one- or two-way ANOVA, as appropriate. All statistical analyses were assessed using SPSS version 11.5 software. A $P$ value $<0.05$ was considered statistically significant.

\section{Results}

\subsection{Kinetics of plasma KTP}

The plasma concentration of KTP was higher than that of GP62 within $28 \mathrm{~h}$ after administration. The maximum plasma concentration $\left(C_{\max }\right)$ was higher $(43.18 \mathrm{nmol} / \mathrm{L}$ vs 30.56 $\mathrm{nmol} / \mathrm{L}$ ) and the $T_{\max }$ was longer ( $4 \mathrm{~h}$ vs $3 \mathrm{~h}$ ) for KTP than for GP62. The terminal elimination half-lives $\left(t_{1 / 2}\right)$ of KTP and GP62, calculated with the method of residuals, were $7.8 \mathrm{~h}$ and $5.7 \mathrm{~h}$, respectively (Figure 1 ).

\subsection{Insulinotropic and hypoglycemic effects of KTP}

Both KTP and GP62 increased insulin secretion and production significantly in SD rats, with KTP being more active than GP62. Time to maximum plasma concentration of insulin was somewhat later for KTP than for GP62, although both were earlier than vehicle (Figure 2).

Blood glucose concentrations of $d b / d b$ mice treated with a single dose of KTP or GP62 were significantly lower than those of vehicle-treated mice within $24 \mathrm{~h}$ or $12 \mathrm{~h}$ after administration $(P<0.05$ each). Importantly, blood glucose concentrations differed significantly in KTP and GP62treated mice beginning $7 \mathrm{~h}$ after administration $(P<0.05)$ (Figure 3).

\subsection{Long-term treatment of $d b / d b$ mice with KTP}

(1) Changes in food and water intake. Following 60 days of treatment with KTP or Exendin-4, the food and water intake of $d b / d b$ mice were significantly lower than before

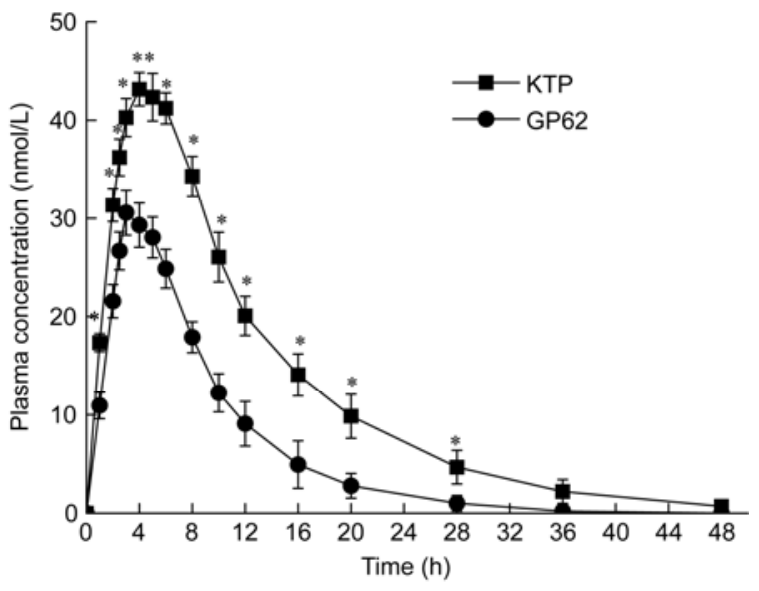

Figure 1 Mean plasma concentrations of KTP and GP62 versus time profiles after a single dose of subcutaneous injection in SD rats. The plasma concentration of KTP was significantly higher than that of GP62 within $28 \mathrm{~h}$ after administration. ${ }^{*} P<0.05$ versus GP62.

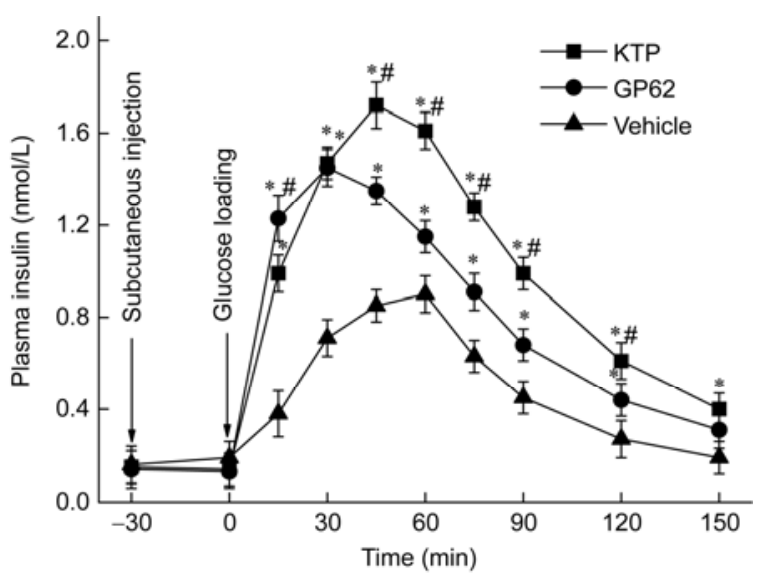

Figure 2 Insulinotropic activities of KTP and GP62. Rats received subcutaneous injection with KTP $(1.2 \mathrm{mg} / \mathrm{kg}$ body weight), GP62 $(1.2 \mathrm{mg} / \mathrm{kg}$ body weight) or an equal volume of vehicle and after $30 \mathrm{~min}$, were orally administered glucose $(2 \mathrm{~g} / \mathrm{kg}, 50 \%$ glucose solution). $* P<0.05$ versus vehicle, $\# P<0.05$ versus GP62.

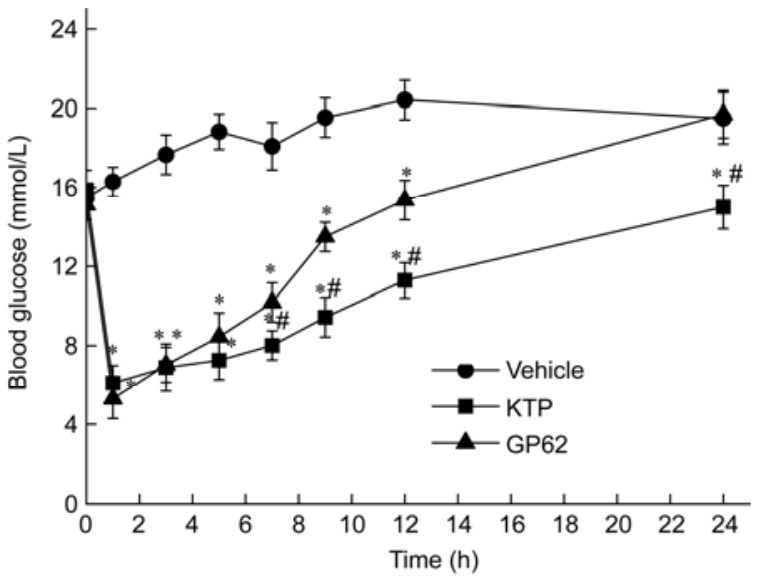

Figure 3 Mean blood glucose concentration versus time profiles after a single dose of subcutaneous injection with $\mathrm{KTP}(1.2 \mathrm{mg} / \mathrm{kg}$ body weight), GP62 $(1.2 \mathrm{mg} / \mathrm{kg}$ body weight) or an equal volume of vehicle in $d b / d b$ mice. $* P<0.05$ versus vehicle, $\# P<0.05$ versus GP62. 
treatment $(P<0.05)$, differences not observed in vehicletreated mice. Moreover, after $60 \mathrm{~d}$, the food and water intake were significantly lower in mice treated with KTP or Exendin-4 than in vehicle-treated mice $(P<0.05)$. Food and water intake, however, did not differ significantly in mice treated with KTP and Exendin-4 (Figure 4 (a) and (b)).

(2) Changes in body weight. The body weights of all $d b / d b$ mice increased continuously throughout the entire experiment. Beginning during week 5, however, the body weight of mice treated with KTP or Exendin-4 was significantly lower than that of mice treated with vehicle $(P<0.05)$ (Figure 5(a)). After $60 \mathrm{~d}$, the body weight gain of $d b / d b$ mice treated with KTP or Exendin-4 was significantly less than that of vehicle-treated mice $(P<0.05)$ (Figure 5(b)), but there were no significant differences between mice treated with KTP and Exendin-4 (Figure 5 (a) and (b)).

(3) Changes in blood glucose and lipid. Compared with vehicle-treated mice, the blood glucose concentrations of mice treated with KTP $(P<0.05)$ and Exendin-4 $(P<0.05)$ were
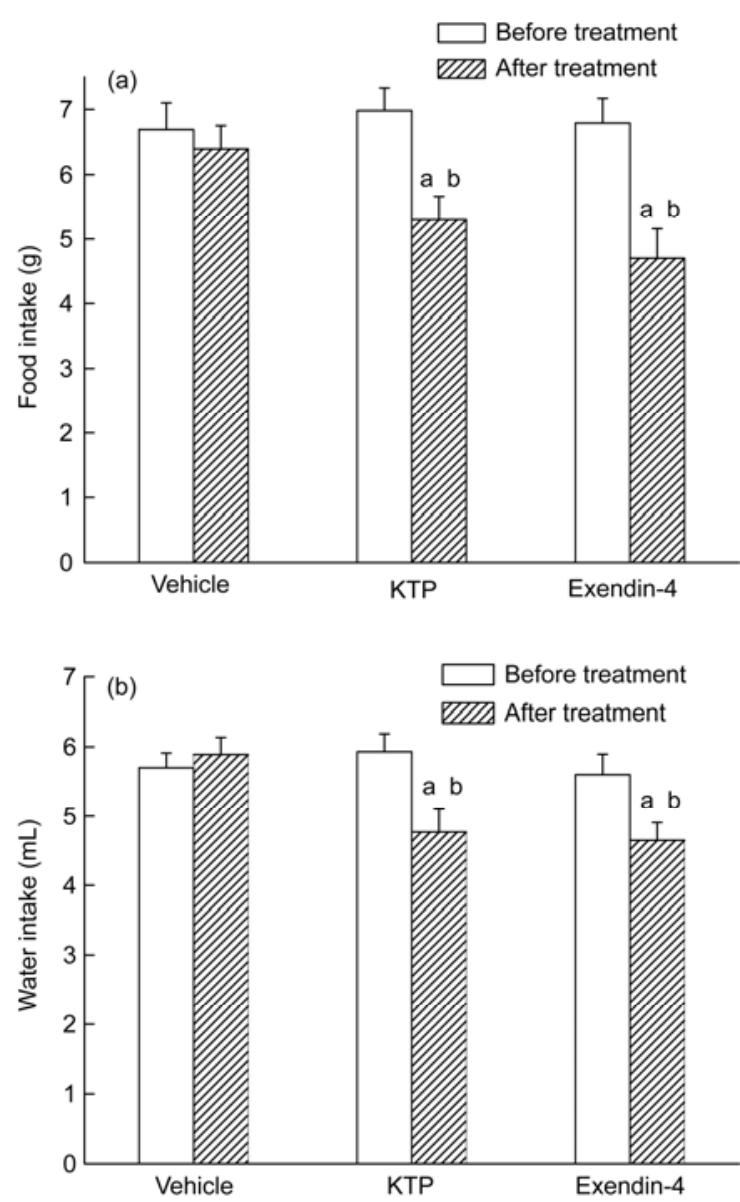

Figure 4 The effects of KTP long-term treatment on food (a) and water (b) intake in $d b / d b$ mice. After 60-d treatment, food and water intake were significantly less than before treatment $(\mathrm{a}, P<0.05)$ and that of vehicle-treated mice $(\mathrm{b}, P<0.05)$ in KTP-treated mice and Exendin-4-treated mice. There was no significant difference between before and after treatment in vehicle-treated mice. a, $P<0.05$ versus before treatment; b, $P<0.05$ versus vehicle. significantly lower at 5, 10,60, 120, and $180 \mathrm{~min}$ after glucose loading, with no differences between the KTP and Exendin-4 groups. However, all three groups had similar blood glucose concentrations at 20 and 30 min (Figure 6).
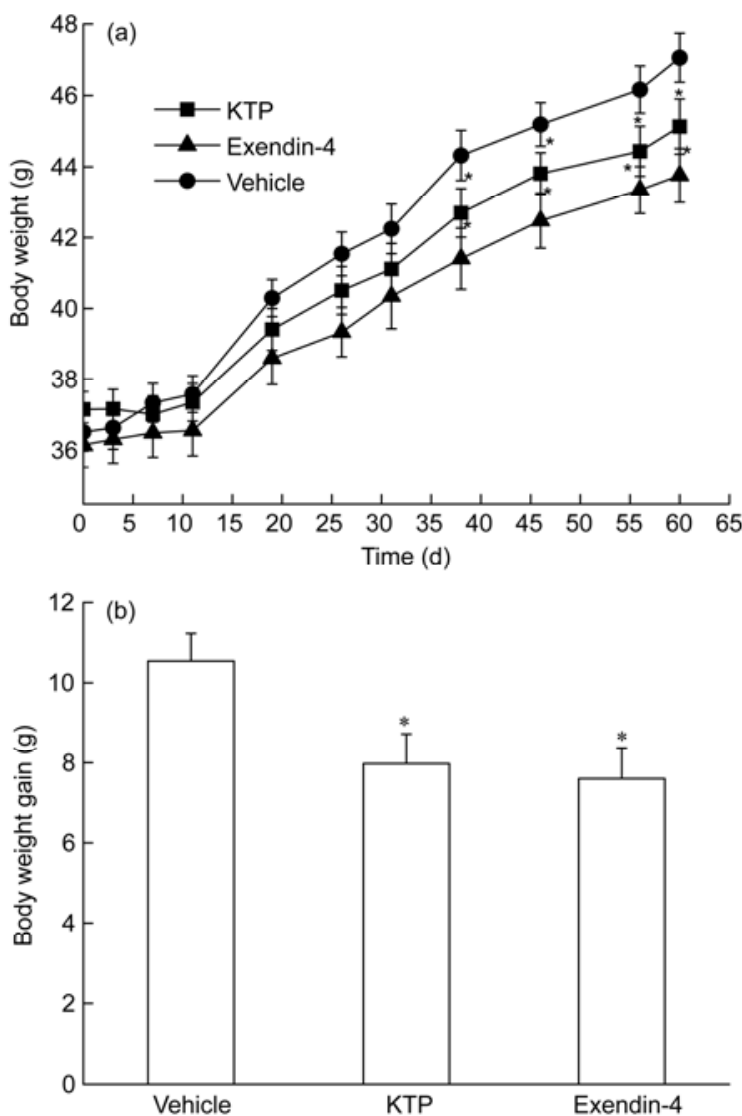

Figure 5 The effects of KTP long-term treatment on body weight (a) and body weight gain (b) in $d b / d b$ mice. The body weight of KTP-treated and Exendin-4-treated mice were significantly lower than that of vehicletreated mice $(P<0.05)$. After $60 \mathrm{~d}$, the body weight gain of KTP-treated and Exendin-4-treated mice were significantly less than that of vehicle-treated mice $(P<0.05)$. $* P<0.05$ versus vehicle.

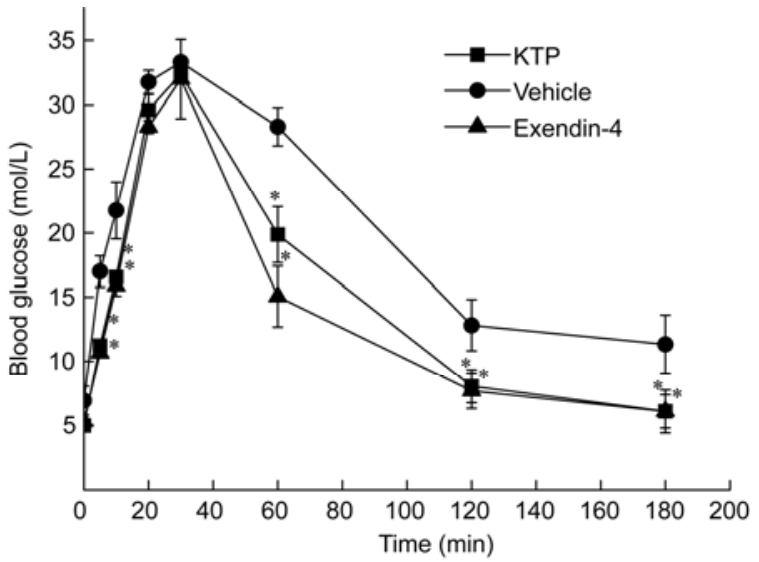

Figure 6 The blood glucose concentration during oral glucose tolerance test performed in $d b / d b$ mice treated with KTP, GP62 or vehicle. $* P<0.05$ versus vehicle. 
Both total cholesterol (TC) and triglyceride (TG) concentrations were significantly lower in $d b / d b$ mice treated with KTP or Exendin-4 than in the vehicle-treated mice $(P<0.05$ each), but no differences in TC and TG concentrations between the KTP and the Exendin-4. High density lipoprotein cholesterol (HDL) and low density lipoprotein cholesterol (LDL) concentrations were similar in all three groups (Table 1).

(4) Morphological changes in pancreas and liver. More and more severe pathological changes were observed in mice treated with vehicle than in mice treated with KTP or Exendin-4. Pancreatic acini showed disordered arrangements, disorganized structures and atrophy, with smaller nuclei and less cytoplasm. Capillary vessels of pancreas islets were seriously congested and the density of islet cells decreased (Figure 7(a)). Although pathological changes were observed in mice treated with KTP or Exendin-4, they were fewer and less severe than in vehicle-treated mice (Figure 7(b) and (c)). More and denser insulin secretion granules, with deeper staining, were observed in mice treated with KTP or Exendin-4 than with vehicle (Figure 7(d)-(f)).

The livers of all mice were yellow in color with fatty particles on the surface. However, the liver surfaces of mice treated with vehicle were more yellow, greasy and rough than those of KTP or Exendin-4-treated mice. Moreover, the livers of vehicle-treated mice were larger than those of mice treated with KTP or Exendin-4.

The livers of vehicle-treated mice showed complete disappearance of hepatic cords, along with severe hydropic degeneration, fatty infiltration and atrophic nucleoli in most hepatic cells, which were irregularly arranged and swollen. Additionally, some hepatic cells seemed to be vacuoles with a cytoskeleton but without a nucleus (Figure 8 (a)). The pathologic changes observed in mice treated with KTP or

Table 1 Changes in blood lipid after long-term treatment ${ }^{\text {a) }}$

\begin{tabular}{lllc}
\hline Group & TC $(\mathrm{mmol} / \mathrm{L})$ & TG $(\mathrm{mmol} / \mathrm{L})$ & HDL $(\mathrm{mmol} / \mathrm{L})$ \\
\hline KTP & $4.0016 \pm 0.1784^{*}$ & $0.9655 \pm 0.0794^{*}$ & $2.0817 \pm 0.0653$ \\
Exendin-4 & $3.8321 \pm 0.2429^{*}$ & $0.8400 \pm 0.0867^{*}$ & $1.9750 \pm 0.0879$ \\
Vehicle & $4.9917 \pm 0.2243$ & $1.3633 \pm 0.0824$ & $1.9433 \pm 0.1124$ \\
\hline
\end{tabular}

a) $* P<0.05$ versus vehicle

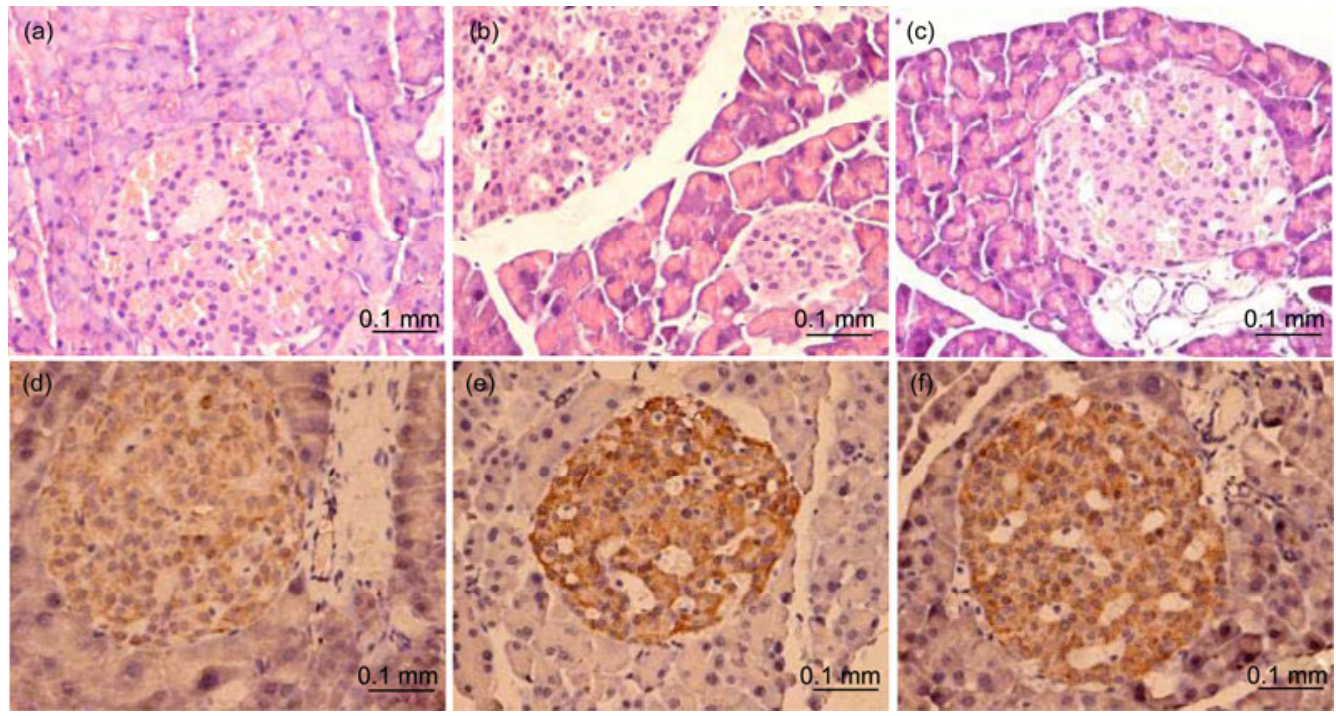

Figure 7 H\&E staining (a)-(c) and immunohistochemical staining (d)-(f) on paraffin sections of pancreas in $d b / d b$ mice treated with vehicle (a) and (d), KTP (b) and (e) or Exendin-4 (c) and (f).
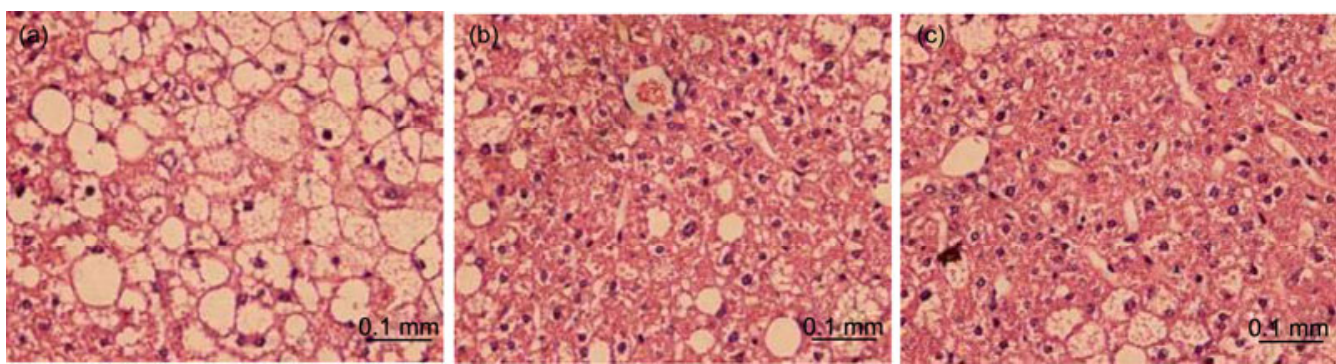

Figure 8 H\&E staining (a)-(c) on paraffin sections of livers in $d b / d b$ mice treated with vehicle (a), KTP (b) or Exendin-4 (c). 
Exendin-4 were less severe (Figure 8 (b) and (c)).

\section{Discussion}

Since thrombin hydrolyzes the amido bond at the $\mathrm{C}$ terminus of $\operatorname{Arg}(\mathrm{R})$ or Lys $(\mathrm{K})$, it can recognize and cleave the LK of GP62 on the C terminus of $\operatorname{Arg}(\mathrm{R})$. Moreover, it is more active in cleaving at $\operatorname{Arg}(\mathrm{R})$ than at Lys (K) [22]. DPPIV has the unique ability to cleave N-terminal Xxx (X)-Pro (P) dipeptides from protein molecules, with its hydrolytic activity affected by $\mathrm{Xxx}(\mathrm{X})$ [23]. To further improve the controlled release of GP62, Arg (R) and Gly (G) in its LK (FNPRGP) were replaced by Lys (K) and Thr (T), respectively, generating a new GLP-1 derivative KTP. The amino acid substitutions may decrease the ability of thrombin and DPPIV to cleave the LK, slowing the release of GLP-1 from KTP. Our results suggested that these substitutions prolonged the half-life of KTP. Moreover, a single dose of KTP was more active than a single dose of GP62 in promoting the secretion and production of insulin and reducing blood glucose concentration, and showed continuous activity over $24 \mathrm{~h}$. Taken together, these findings showed that the release of GLP-1 from KTP was better controlled than from GP62. Although the two amino acid substitutions doubtless played an important role in determining the lifetime of KTP, the contribution of each to hydrolysis by thrombin and DPPIV remains unclear.

Although several GLP-1 derivatives have been prepared [19], their in vivo activity, resulting from hydrolysis by thrombin and DPPIV, remains unclear. We found that longterm $(60 \mathrm{~d})$ treatment with KTP had therapeutic effects on type 2 diabetes in $d b / d b$ mice.

Type 2 diabetes mellitus is a disorderly metabolic endocrine disease that accompanies obesity, hyperglycemia, hyperlipidemia, damaged pancreas, and fatty liver. Our findings indicated that treatment with KTP could alleviate all of these symptoms of type 2 diabetes.

In contrast to subcutaneous administration, a continuous intravenous drip of native GLP-1 significantly decreased food and water intake in Wister rats fed a high-fat diet [24], but these effects required high doses of GLP-1 because of its transient half-life. We found, however, that two daily subcutaneous injections of KTP significantly reduced food and water intake in $d b / d b$ mice, affecting changes in body weight. Weight gain was lower in mice treated with KTP or Exendin-4 than vehicle. Moreover, in contrast to the effects of NN2211 (a long-acting GLP-1 derivative) on body weight loss in Wister rats [25], the body weight of all $d b / d b$ mice continuously increased throughout the entire treatment period, a difference that may be due to differences in the animal models tested.

Hyperglycemia and dyslipidemia are typical symptoms of diabetes in $d b / d b$ mice. Long-term treatment with KTP markedly improved glucose tolerance in $d b / d b$ mice within
$15 \mathrm{~min}$ and after $1 \mathrm{~h}$ after glucose loading. Thus, KTP enhanced the first phase of insulin secretion and the second phase of insulin synthesis and secretion. Treatment with KTP also significantly decreased the concentrations of blood $\mathrm{TG}$ and TC in $d b / d b$ mice. The changes of glucose tolerance and blood lipid might be related to the inhibition of food and water intake and pancreas improvements. We found, however, that serum HDL and LDL concentrations were similar in mice administered KTP and vehicle, which may be because of the relatively short treatment or the physiological characteristics of the animal model.

The pancreas and liver of $d b / d b$ mice aged over 5 weeks are usually abnormal. Treatment with KTP may alleviate the deterioration of the pancreas by enhancing the synthesis and secretion of insulin, thus reducing the toxic effects of hyperglycemia on the pancreas. Furthermore, we found that KTP ameliorated fatty liver in $d b / d b$ mice. Thus, KTP may act via two mechanisms: reducing blood lipid concentration by inhibiting food intake and enhancing endogenous lipid metabolism by improving the function of the pancreas islets.

\section{Conclusions}

Long-term administration of KTP induced anorexia, reduced food intake, had a good effect on weight gain, improved blood glucose tolerance and lipid concentrations and ameliorated pancreas damage and fatty liver in $d b / d b$ mice. KTP may therefore affect the development of type 2 diabetes and may be a promising new treatment in patients with this condition.

The authors are grateful to Li YueQin for kind discussion and suggestions which improve our results.

1 Ørskov C. Glucagon-like peptide-1, a new hormone of the stimula-entero-insular axis. Diabetologia, 1992, 35: 701-711

2 Fehmann H C, Goke R, Goke B. Cell and molecular biology of the incretin hormones glucagon-like peptide-1 and glucose-dependent insulin releasing polypeptide. Endocr Rev, 1995, 16: 390-410

3 Holz G G, Kuhtreiber W M, Habener J F. Pancreatic beta-cells are rendered glucose-competent by the insulinotropic hormone glucagon-like peptide-1 (7-37). Nature, 1993, 361: 362-365

4 Holst J J, Ørskov C, Nielsen O V, et al. Truncated glucagon-like peptide 1, an insulin-releasing hormone from the distal gut. FEBS Lett, 1987, 211: 169-174

5 Naslund E, Barkeling B, King N, et al. Energy intake and appetite are suppressed by glucagon-like peptide-1 (GLP-1) in obese men. Int J Obes Rel Metab Disord, 1999, 68: 304-311

6 Naslund E, Gutniak M, Skogar S, et al. Glucagon-like peptide 1 increases the period of postprandial satiety and slows gastric emptying in obese men. Am J Clin Nutr, 1998, 23: 525-530

7 Edvell A, Lindstrom P. Initiation of increased pancreatic islet growth in young normoglycemic mice. Endocrinology, 1999, 140: 778-783

8 Gutniak M, Ørskov C, Holst J J, et al. Antidiabetogenic effect of glucagon-like peptide-1 (7-36) amide in normal subjects and patients with diabetes mellitus. New Engl J Med, 1992, 326: 1316-1322 
9 Gutniak M K, Linde B, Holst J J, et al. Subcutaneous injection of the incretin hormone glucagon-like peptide 1 abolishes postprandial glycemia in NIDDM. Diabetes Care, 1994, 17: 1039-1044

10 Nauck M A, Kleine N, Ørskov C, et al. Normalization of fasting hyperglycaemia by exogenous glucagon-like peptide 1 (7-36 amide) in type 2 (non-insulin-dependent) diabetic patients. Diabetologia, 1993, 36: 741-744

11 Nauck M A, Wollschlager D, Werner J, et al. Effects of subcutaneous glucagon-like peptide 1 (GLP-1 [7-36 amide]) in patients with NIDDM. Diabetologia, 1996, 39: 1546-1553

12 Nauck M A, Sauerwald A, Ritzel R, et al. Influence of glucagon-like peptide 1 on fasting glycemia in type 2 diabetic patients treated with insulin after sulfonylurea secondary failure. Diabetes Care, 1998, 21: 1925-1931

13 Qualmann C, Nauck M A, Holst J J, et al. Insulinotropic actions of intravenous glucagon-like peptide-1 (GLP-1) [7-36 amide] in the fasting state in healthy subjects. Acta Diabetol, 1995, 32: 13-16

14 Toft-Nielsen M B, Madsbad S, Holst J J. Continuous subcutaneous infusion of glucagon-like peptide 1 lowers plasma glucose and reduces appetite in type 2 diabetic patients. Diabetes Care, 1999, 22: 1137-1143

15 Mentlein R, Gallwitz B, Schmidt W E. Dipeptidyl-peptidase IV hydrolyses gastric inhibitory polypeptide, glucagon-like peptide-1 (7-36) amide, peptide histidine methionine and is responsible for their degradation in human serum. Eur J Biochem, 1993, 214: 829-835

16 Kieffer T J, McIntosh C H, Pederson R A. Degradation of glucose-dependent insulinotropic polypeptide and truncated glucagonlike peptide 1 in vitro and in vivo by dipeptidyl peptidase IV. Endocrinology, 1995, 136: 3585-3596
17 Kumar M D, Baboota S, Ahuja A, et al. Recent advances in protein and peptide drug delivery systems. Drug Delivery, 2007, 4: 141-151

18 Pawar R, Ben Ari A, Domb A J. Protein and peptide parenteral controlled delivery. Expert Opin Biol Ther, 2004, 4: 1203-1212

19 Li H J, Ma Y, Chen Y, et al. A protease-based strategy for the controlled release of therapeutic peptides. Angew Chem Int Ed Engl, 2010, 49: 4930-4933

20 Marques C M M, Motta V F, Torres T S, et al. Beneficial effects of exercise training (treadmill) on insulin resistance and nonalcoholic fatty liver disease in high-fat fed C57BL/6 mice. Braz J Med Biol Res, 2010, 43: 467-475

21 Julio C F, Rebeca O D, Caroline F S, et al. A mouse model of metabolic syndrome: Insulin resistance, fatty liver and non-alcoholic fatty pancreas disease (NAFPD) in C57BL/6 mice fed a high fat diet. J Clin Biochem Nutr, 2010, 46: 212-223

22 Su Z, Vinogradova A, Koutychenko A, et al. Rational design and selection of bivalent peptide ligands of thrombin incorporating P4-P1 tetrapeptide sequences: from good substrates to potent inhibitors. Protein Eng Des Sel, 2004, 17: 647-657

23 Alberto D T, Carlos G A, Silvia C, et al. Application of the dipeptidyl peptidase IV (DPPIV/CD26) based prodrug approach to different amine-containing drugs. J Med Chem, 2010, 53: 559-572

24 Turton M D, O'Shea D O, Gunn I, et al. A role for glucagon-like peptide-1 in the central regulation of feeding. Nature, 1996, 379: $69-72$

25 Larsen P J, Fledelius C, Knudsen L B, et al. Systemic administration of the long-acting GLP-1 derivative NN2211 induces lasting and reversible weight loss in both normal and obese rats. Diabetes, 2001, 50: 2530-2539

Open Access This article is distributed under the terms of the Creative Commons Attribution License which permits any use, distribution, and reproduction in any medium, provided the original author(s) and source are credited. 